\title{
PROFIL PSORIASIS DI POLIKLNIK KULIT DAN KELAMIN RSUP PROF. DR. R. D. KANDOU MANADO PERIODE JANUARI-DESEMBER 2012
}

\author{
${ }^{1}$ Anggelina Moningka \\ ${ }^{2}$ Renate T. Kandou \\ ${ }^{2}$ Nurdjanah J. Niode
}

\author{
${ }^{1}$ Kandidat Skripsi Fakultas Kedokteran Universitas Sam Ratulangi Manado \\ ${ }^{2}$ Bagian/SMF Kulit dan Kelamin RSUP Prof. Dr. R. D. Kandou Manado \\ Email: angelakimmeilin@gmail.com
}

\begin{abstract}
Psoriasis is a chronic inflammatory skin disease which was first identified in 1841. However, this condition was recognized centuries earlier. This disease affects the outer side of elbows, knees, and scalps. In psoriatic patients, skin cells regenerate faster than their normal rate (28 days), which is approximately every 2 days. This study aimed to obtain the profile of psoriatic cases in Prof. Dr. R. D. Kandou Hospital Manado from January to December 2012. This was a descriptive and retrospective study on the number of cases, number of patients, sex, age, and occupation of patients, as well as types of treatment of psoriasis. The results showed that of 48 cases of psoriasis (1.21\%), the highest number of cases found was psoriasis vulgaris (58\%), affecting males (56.25\%), and in the age group of 45-64 years old (58.33\%). The majority of the patients had unknown occupation (31.25\%) and the most common type of treatment was a combination therapy of topical corticosteroid and antihistamine (29.17\%).
\end{abstract}

Keywords: psoriasis

\begin{abstract}
Abstrak: Psoriasis adalah penyakit kulit kronik dan meradang yang diidentifikasi sejak tahun 1841 namun kemunculannya telah diketahui beberapa abad sebelumnya. Penyakit ini mengenai bagian luar siku, lutut atau kulit kepala. Pada psoriasis sel-sel kulit tumbuh terlalu cepat yang biasanya pada orang normal terjadi 28 hari, sedangkan pada pasien psoriasis berlangsung lebih cepat yaitu sekitar 2 hari. Penelitian ini bertujuan untuk mendapatkan profil psoriasis di RSUP. Prof. Dr. R. D. Kandou Manado periode Januari-Desember 2012. Penelitian ini bersifat deskriptif retrospektif tentang jumlah kasus, jumlah pasien, jenis kelamin, umur, pekerjaan, dan jenis pengobatan. Hasil penelitian menunjukkan bahwa dari 48 kasus psoriasis (1,21\%), terbanyak ialah kasus psoriasis vulgaris (58\%), jenis kelamin laki-laki (56,25\%), dan kelompok umur 45-64 tahun (58,33\%). Pekerjaan terbanyak ialah yang tidak diketahui pekerjaanya (31,25\%), dan jenis pengobatan yang terbanyak ialah terapi kombinasi kortikosteroid topikal dan antihistamin (29,17\%).
\end{abstract}

Kata kunci: psoriasis

Psoriasis adalah penyakit kulit dengan penyebab autoimun, bersifat kronik residif, yang ditandai dengan adanya bercak-bercak eritema berbatas tegas dengan skuama kasar, berlapis-lapis, dan transparan; disertai fenomena tetesan lilin, tanda Auspits dan Kobner. ${ }^{1,2}$ Penyakit ini sangat dipengaruhi oleh faktor genetik dan prevalensinya beragam berdasarkan suku. Insidens pada pria lebih banyak daripada wanita, terdapat pada semua usia, tetapi umumnya pada orang dewasa. $^{2}$

Data nasional prevalensi psoriasis di Indonesia belum diketahui, namun di 
Rumah Sakit Umum Pusat (RSUP) H. Adam Malik Medan, berdasarkan data yang diperoleh dari rekam medis selama periode Januari-Desember 2010, dari total 3.230 orang yang berobat ke Poliklinik Ilmu Kesehatan Kulit dan Kelamin, 34 pasien $(1,05 \%)$ di antaranya merupakan pasien dengan diagnosis psoriasis. Dari jumlah tersebut 16 pasien (47\%) berjenis kelamin pria dan 18 pasien (52,9\%) berjenis kelamin wanita. Di RS Dr. M. Djamil Padang selama tahun 2000-2005 insiden psoriasis ber-kisar 1,6\%-2,6. Di Poliklinik Penyakit Kulit dan Kelamin RSUP Sanglah Denpasar pada Januari sampai Desember 2009 tercatat 156 kasus baru psoriasis dari 10.856 kunjungan (1,44\%). Penelitian Peggy dkk di RSUP. Prof. Dr. R. D. Kandou Manado periode Januari 2006Desember 2008 terdapat 169 kasus psoriasis dari 11730 kunjungan(1,44\%), pada tahun 2006 ditemukan 62 kasus, tahun 2007 terdapat 51 kasus dan tahun 2008 sebanyak 56 kasus. $^{3}$

Dengan semakin berkembangnya bidang dermatologi dan semakin banyaknya ditemukan rejimen baru yang efektif untuk pengobatan psoriasis maka penulis merasa tertarik untuk mengadakan penelitian tentang psoriasis di Poliklinik Kulit dan Kelamin RSUP Prof. DR. R. D. Kandou Manado periode Januari-Desember 2012.

\section{METODE PENELITIAN}

Penelitian ini merupakan penelitian deskriptif retrospektif dengan melihat dan mencatat kembali catatan rekam medik pasien psoriasis yang tercatat menderita penyakit kulit di Poliklinik Kulit dan Kelamin RSUP Prof. Dr. R. D. Kandou Manado periode Januari-Desember 2012. Sampel penelitian yaitu semua kasus baru dan lama yang tercatat menderita psoriasis. Variabel penelitian terdiri atas jumlah kasus, jenis kelamin, umur, pekerjaan, tipe psoriasis, dan penanganan.

\section{HASIL PENELITIAN}

Penelitian deskriptif retrospektif mengenai psoriasis dilakukan di Poliklinik
Kulit dan Kelamin serta Instalasi Rekam Medik RSUP Prof. Dr. R. D. Kandou Manado periode Januari-Desember 2012.

Tabel 1. Distribusi jumlah pasien di Poliklinik Kulit dan Kelamin RSUP Prof. DR. R. D. Kandou Manado tahun 2012

\begin{tabular}{ccc}
\hline Penyakit & $\mathbf{N}$ & $\mathbf{\%}$ \\
\hline Psoriasis & 48 & 1,21 \\
Penyakit kulit lainnya & 3975 & 98,79 \\
\hline Total & 4023 & 100 \\
\hline
\end{tabular}

Dari hasil distribusi seluruh pasien baru dan lama yang berobat di Poliklinik Kulit dan Kelamin RSUP Prof. DR. R. D. Kandou Manado periode Januari-Desember tahun 2012 berjumlah 4023 pasien dan yang terdiagnosis dengan psoriasis berjumlah 48 pasien $(1,21 \%)$.

Tabel 2. Distribusi jumlah pasien psoriasis di Poliklinik Kulit dan Kelamin RSUP Prof. DR. R. D. Kandou Manado tahun 2012

\begin{tabular}{ccc}
\hline Penyakit & N & $\mathbf{\%}$ \\
\hline Psoriasis Vulgaris & 28 & 58,33 \\
Sebopsoriasis & 6 & 12,50 \\
Psoriasis Gutata & 7 & 14,60 \\
Psoriasis Pustulosa & 5 & 10,41 \\
Generalisata Akut & & \\
Eritroderma Psoriasis & 2 & 4,16 \\
\hline Total & 48 & 100 \\
\hline
\end{tabular}

Dari distribusi jumlah pasien psoriasis didiagnosis terbanyak ialah Psoriasis Vulgaris 28 orang (58,33\%) dan yang paling sedikit Eritroderma Psoriasis 2 orang (4,16\%).

Tabel 3. Distribusi jumlah pasien psoriasis menurut jenis kelamin di Poliklinik Kulit dan Kelamin RSUP Prof. DR. R. D. Kandou Manado tahun 2012

\begin{tabular}{ccc}
\hline Jenis kelamin & $\mathbf{N}$ & $\mathbf{\%}$ \\
\hline Laki-laki & 27 & 56,25 \\
Perempuan & 21 & 43,75 \\
\hline Total & 48 & 100 \\
\hline
\end{tabular}

Dari hasil distribusi ini diketahui bahwa laki-laki 27 orang (56,25\%) lebih 
banyak menderita psoriasis daripada perempuan 21 orang (43,75\%).

Tabel 4. Distribusi jumlah pasien Psoriasis menurut umur di Poliklinik Kulit dan Kelamin RSUP Prof. DR. R. D. Kandou Manado tahun 2012

\begin{tabular}{ccc}
\hline Golongan umur & $\mathbf{N}$ & $\mathbf{\%}$ \\
\hline $0-<1$ & 0 & 0 \\
$1-<5$ & 0 & 0 \\
$5-14$ & 2 & 4,17 \\
$15-24$ & 5 & 10,42 \\
$25-44$ & 9 & 18,75 \\
$45-64$ & 28 & 58,33 \\
$\geq 65$ & 4 & 8,33 \\
Total & 48 & 100 \\
\hline
\end{tabular}

Dari penelitian ini juga diketahui bahwa pasien psoriasis terbanyak pada kelompok umur 45-64 tahun dengan jumlah 28 kasus $(58,33 \%)$ dan yang terendah ada pada kelompok umur 5-14 tahun dengan 2 kasus (4,17\%). Tidak tedapat pasien psoriasis pada kelompok umur $0-<1$ tahun dan $1-<5$ tahun.

Tabel 5. Distribusi jumlah pasien psoriasis menurut pekerjaan di Poliklinik Kulit dan Kelamin RSUP Prof. DR. R. D. Kandou Manado tahun 2012

\begin{tabular}{ccc}
\hline Pekerjaan & $\mathbf{N}$ & $\mathbf{\%}$ \\
\hline Tidak diketahui & 15 & 31,25 \\
Mahasiswi & 1 & 2,08 \\
PNS & 5 & 10,4 \\
IRT & 6 & 12,5 \\
Petani & 8 & 16,67 \\
Guru & 7 & 14,59 \\
Swasta & 2 & 4,18 \\
Tukang & 3 & 6,25 \\
Sopir & 1 & 2,08 \\
Total & 48 & 100 \\
\hline
\end{tabular}

Data penelitian ini menunjukkan terbanyak pasien psoriasis tidak diketahui pekerjaannya sebanyak 15 kasus (31,25\%) dan yang terendah mahasiswa dan sopir masing-masing 1 kasus (2,08\%).

Data Tabel 6 menunjukkan bahwa jenis terapi obat yang paling banyak digunakan pada kasus psoriasis ialah terapi obat kombinasi kortikosteroid topikal dan antihistamin sebanyak 14 kasus (29,17\%), diikuti oleh terapi emolien dan kortikosteroid topikal sebanyak 11 kasus (22,91\%), dan penggunaan kombinasi topikal dan antijamur sebanyak 6 kasus (12,5\%) khusus untuk kasus sebopsoriasis. Terapi dengan kasus tersedikit yaitu dengan kombinasi topikal dan kortikosteroid sistemik 2 kasus (4,17\%).

Tabel 6. Distribusi menurut jenis pengobatan di RSUP Prof. DR. R.D Kandou Manado tahun 2012

\begin{tabular}{|c|c|c|}
\hline Terapi & $\mathbf{N}$ & $\%$ \\
\hline \multicolumn{3}{|l|}{ Topikal } \\
\hline - Emolien & 3 & 6,25 \\
\hline - $\quad$ Kortikosteroid (Ks) & - & \\
\hline $\begin{array}{ll}- & \text { Kombinasi (emolien } \\
& +\mathrm{Ks} \text { ) }\end{array}$ & 11 & 22,91 \\
\hline \multicolumn{3}{|l|}{ Sistemik } \\
\hline - Kortikosteroid & - & - \\
\hline - $\quad$ Anti jamur & - & - \\
\hline - $\quad$ Anti histamine & - & - \\
\hline - Anti bakteri & - & - \\
\hline \multicolumn{3}{|l|}{ Kombinasi } \\
\hline $\begin{array}{ll}\text { - } & \text { Emolien+anti } \\
& \text { histamin }\end{array}$ & 7 & 14,59 \\
\hline $\begin{array}{l}\text { - } \quad \text { Ks topikal+anti } \\
\text { histamine }\end{array}$ & 14 & 29,17 \\
\hline $\begin{array}{ll}\text { - } & \text { Kombinasi } \\
& \text { topikal+Ks sistemik }\end{array}$ & 2 & 4,17 \\
\hline $\begin{array}{ll}\text { - } & \text { Kombinasi } \\
& \text { topikal+anti jamur }\end{array}$ & 6 & 12,5 \\
\hline $\begin{array}{ll}\text { - } & \text { Kombinasi } \\
& \text { topikal+anti bakteri }\end{array}$ & 5 & 10,41 \\
\hline Total & 48 & 100 \\
\hline
\end{tabular}

\section{BAHASAN}

Pada penelitian ini, sampel yang diambil adalah seluruh kasus lama dan baru psoriasis yang berobat di Poliklinik Kulit dan Kelamin RSUP Prof. DR. R. D. Kandou Manado periode Januari-Desember 2012.

Diperoleh jumlah kasus psoriasis sebanyak 48 kasus dari 4023 kunjungan di poliklinik kulit dan kelamin periode Januari-Desember 2012 (Tabel 1). Data ini menunjukkan penurunan dari hasil penelitian sebelumnya yang dilakukan oleh Peggy et al. di tempat yang sama periode 
2006-2008; pada tahun 2006 ditemukan 62 kasus, tahun 2007 dengan 51 kasus dan pada tahun 2008 terdapat 56 kasus. $^{4}$ Kemungkinan terdapatnya penurunan kasus psoriasis pada tahun 2012 dibanding pada tahun-tahun sebelumnya karena adanya rumah sakit baru dan dokter-dokter spesialis kulit baru di Manado, sehingga mungkin banyak pasien psoriasis lainnya yang telah memeriksakan diri ketempat tersebut.

Berdasarkan hasil penelitian maka ditemukan kasus Psoriasis Vulgaris 28 kasus (58,33\%), Sebopsoriasis 6 kasus (12,50\%), Psoriasis Gutatta 7 kasus (14,60\%), Psoriasis Pustulosa Generalisata Akut 5 kasus $(10,41 \%)$, dan Eritroderma Psoriasis 2 kasus (4,16\%) dapat dilihat pada tabel 2. Hal ini sesuai dengan salah satu kepustakaan yang menyatakan bahwa psoriasis vulgaris merupakan psoriasis yang umum diderita. ${ }^{5}$

Dari distribusi jenis kelamin didapatkan laki-laki lebih banyak yang menderita psoriasis yaitu sebesar 27 kasus (56,25\%) dan perempuan adalah 21 kasus (43,75\%). Pada beberapa kepustakaan juga menjelaskan hal yang sama seperti yang ditemukan pada tabel 3, yaitu insiden psoriasis lebih banyak pada laki-laki dibanding pada perempuan. ${ }^{2}$

Distribusi umur menunjukkan bahwa kasus terbanyak terdapat pada kelompok umur 45-64 tahun yaitu sebesar 28 kasus (58,33\%). Selama setahun yaitu dari Januari-Desember 2012, tidak ditemukan penderita Psoriasis pada kelompok umur 0$<1$ dan $1-<5$ tahun, pada penderita psoriasis dalam kelompok umur 5-14 tahun hanya berjumlah 2 pasien (4,17\%). Pada rentang umur 25-44 tahun menempati urutan kedua terbanyak yaitu 9 kasus (18,75\%), yang dapat dilihat pada tabel 4. Dari hasil yang didapatkan, diduga bahwa penyebab psoriasis lebih banyak terjadi pada rentang usia 45-64 tahun karena pada rentang usia ini mungkin faktor-faktor psikis seperti stress adalah penyebabnya. Hasil ini didukung dengan salah satu kepustakaan yang mengatakan bahwa 68\% penderita psoriasis menyatakan stress dan kegelisahan menyebabkan penyakitnya lebih berat dan hebat. ${ }^{6}$

Dari jenis pekerjaannya yang dilihat pada tabel 5, menunjukkan pasien terbanyak psoriasis tidak diketahui pekerjaannya sebanyak 15 kasus (31,25\%), diikuti oleh petani yang berjumlah 8 kasus (16,67\%), kemudian berturut-turut yang bekerja sebagai guru dengan 7 kasus (14,59\%), IRT 6 kasus (12,5\%), PNS 5 kasus $(10,4 \%)$, tukang 3 kasus $(6,25 \%)$, pegawai swasta 2 (4,18\%) kasus dan mahasiswa dan sopir masing-masing 1 kasus (2,08\%). Terbanyak pada petani mungkin karena penggunaan sepatu boots dalam melakukan aktifitasnya sehari-hari di sawah. Dimana suhu yang lembab mungkin merupakan penyebab munculnya psoriasis.

Dari data pada tabel 6 didapatkan bahwa jenis terapi obat yang paling banyak digunakan pada kasus psoriasis adalah terapi obat kombinasi kortikosteroid topikal dan antihistamin sebanyak 14 kasus (29,17\%), diikuti oleh terapi emolien dan kortikosteroid topikal sebanyak 11 kasus (22,91\%), dan penggunaan kombinasi topikal dan antijamur sebanyak 6 kasus (12,5\%) khusus untuk kasus sebopsoriasis, dan terapi dengan kasus tersedikit yaitu dengan kombinasi topikal dan kortikosteroid sistemik 2 kasus (4,17\%).

\section{SIMPULAN}

Dari hasil penelitian retrospektif penderita psoriasis di Poliklinik Kulit dan Kelamin RSUP Prof. DR. R. D. Kandou periode Januari-Desember 2012 dapat disimpulkan jumlah kasus psoriasis yang berobat di Poliklinik Kulit dan Kelamin RSUP Prof. DR. R. D. Kandou periode Januari-Desember 2012 sebesar 48 kasus (1,21\%) dari 4023 kasus, ditemukan lakilaki lebih banyak dibanding perempuan, umur 45-64 tahun merupakan kelompok umur terbanyak, terbanyak pasien tidak tercatat pekerjaannya, dan jenis terapi terbanyak ialah kombinasi kortikosteroid topikal dan antihistamin. 


\section{SARAN}

Kelengkapan data pasien di catatan rekam medik dan buku register di bagian instalasi rekam medik sebaiknya dilakukan dengan baik agar data yang diperoleh akurat.

Perlu dilakukan penelitian setiap tahun agar dapat diperoleh angka prevalensi setiap tahun.

\section{DAFTAR PUSTAKA}

1. Gudjonsson JE, Elder JT. Psoriasis. In: Wolff K, Goldsmith LA, Katz SI, Gilchrest BA, Paller AS, Leffel DJ, editors. Fitzpatrick's Dermatology in General Medicine (Edisi ke-7). New York: McGraw Hill, 2008; p 169-93.

2. Djuanda A. Dermatosis Eritroskuamosa. In: Djuanda A, Mochtar H, Siti A, editors. Ilmu Penyakit Kulit dan Kelamin (Edisi ke-6). Jakarta: Fakultas Kedokteran Universitas
Indonesia, 2013; p. 189-95.

3. Pardasani, Asha, Steven RF, Adele RC. Treatment of psoriasis: An algorithmbased approach for primary care physicians: American family physician. Available from: http://www.aafp.org/afp/20000201/72 5.html.

4. Pomantow PM. Profil Psoriasis di Poliklinik Kulit dan Kelamin RSUP. Prof. Dr. R. D. Kandou Manado periode Januari 2006-Desember 2008. Karya Tulis Ilmiah Sarjana Kedokteran. Manado: FK Unsrat, 2009.

5. Mayo Clinic. Disease and conditions. Test and disgnosis. Available from: http://www.mayoclinic.org/diseasesconditions/psoriasis/basics/testsdiagnosis/con-20030838.

6. National Psoriasis Foundation. Psoriasis question and answer. Available from: http://psoriasis.org. 